\title{
READING COMPREHENSION RESEARCH AND LINGUISTIC PRAGMATICS: MAPPING OUT SOME UNRECOGNIZED INTERDISCIPLINARY COMMON GROUND
}

\author{
Melinda Sinclair \\ Department of General Linguistics \\ University of Stellenbosch
}

\section{Introduction}

On the whole, research into the various aspects of natural language and language use is characterized by a lack of unity and coherence (see e.g. Verschueren, 1987; Castelfranchi \& Poggi, 1987; Nuyts, 1987; Nuyts, 1992). Nuyts (1992:3-4) describes the current situation in language research in rather negative terms :

"At present, one can hardly speak of a coherent 'science of language'. At best, there is a 'conglomerate of fields and domains of inquiry into language', each of which has its own object of investigation (some aspect or dimension of natural language), terminology, research methods, and/or descriptive systems. Of course, there is nothing wrong with the fact that language is approached from many different angles and in many different ways. On the contrary: given its extreme complexity and manysidedness, this will be inevitable. But the point is that there appears to be no coherence behind the diversity. Most subdomains tend to remain isolated, because different terminology obstructs communication and/or because there is little interest in what is going on in other subdomains, obvious relationships notwithstanding."

As regards interdisciplinary contact, the relationship between reading comprehension research and linguistic pragmatics is no different from that typical within language research. The former is concerned with the mental skills and abilities involved in the interpretation of written utterances, or texts. The latter field is concerned with the interpretation of utterances in context. And in recent conceptualizations, pragmatics is explicitly presented as being concerned with the mental systems and processes involved in such interpretation - see e.g. (Nuyts, 1992:3ff.; Davis, 1991:4; Chametzky, 1992:69; Blakemore, 1992:iv, 4; Sperber and Wilson 1986:vii, 32), to mention but a few examples. "Obvious relationships notwithstanding", to 
quote Nuyts (1992:3-4), the two fields have on the whole developed in isolation from each other. This mutual isolation is strikingly illustrated by the limited overlap between the references cited in the linguistic pragmatic literature and those cited in the reading comprehension literature. The exceptions often involve a limited attempt to link up H. P. Grice's $(1975 ; 1978)$ influential views on conversational implicature with inferencing in reading comprehension. See for example (Morgan \& Green, 1980) for an attempt by pragmaticists to link up Grice's ideas with reading comprehension, and (Oakhill \& Garnham, 1988:31-32) for a similar attempt by reading comprehension researchers.

Despite their mutual isolation, there is nevertheless a remarkable degree of convergence between recent work in reading comprehension research and recent work in linguistic pragmatics. This convergence relates specifically to the mental entities which are assumed in the two fields to underlie reading comprehension and utterance interpretation, respectively. The aim of this article is to map out the 'common ground' between recent findings on this issue in reading comprehension research and in linguistic pragmatics, and to assess its significance for both reading comprehension research and linguistic pragmatics. On the reading comprehension side, the primary focus is on the hypothesis that the skills and abilities that underlie reading comprehension are essentially the same as those that underlie listening comprehension. On the linguistic pragmatic side, the focus is on the hypothesis that utterance interpretation is to a significant extent regulated by general-purpose cognitive principles.

\section{The target hypotheses}

\subsection{Reading comprebension research: The single comprehension process bypothesis}

The relation between the skills and abilities underlying reading comprehension and those underlying listening comprehension is a major issue in the literature - see for example Horowitz \& Samuels (1987). One of the views put forward in the literature is that reading comprehension is not a special skill, separate from listening comprehension. Horowitz \& Samuels (1987:33) call the view that listening and reading comprehension involve essentially the same linguistic and cognitive skills and abilities "the single comprehension process hypothesis". They (1987:33) provide the following formulation of this hypothesis:

\footnotetext{
"Listening and reading comprehension show similar cognitive processing. The fluent reader is characterized as decoding print to the phonological representation and then processing the phonological representation as though it were coming through an auditory channel."
} 
The single comprehension process hypothesis is today widely accepted within reading comprehension research - see for example the references cited by Horowitz \& Samuels (1987:33), the recent papers by Stothard \& Hulme (1992), Hoover \& Gough (1990), Vellutino, Scanlon, Small \& Tanzman (1991), and also the references given in the latter two papers to earlier works in which this hypothesis is adopted.

Hoover \& Gough (1990) provide an extensive exposition of the single comprehension process 0 hypothesis under the title "the simple view of reading". In terms of this view - which Hoover o \& Gough (1990:127-8) trace back to Fries (1963) - reading consists of only two components: $\underset{F}{J}$ decoding of graphic shapes into linguistic forms and linguistic comprehension. Decoding is indefined as "efficient word recognition: the ability to rapidly derive a representation from -printed input that allows access to the appropriate entry in the mental lexicon, and thus, the ¿े retrieval of semantic information at the word level" (Hoover \& Gough 1990:131). In the rest Oof this discussion the more specific term "graphic decoding" will be used to denote this ${ }_{\infty}$ component of reading. Linguistic comprehension is defined by Hoover \& Gough (1990:131) as $\sigma^{n}$ "the ability to take lexical information (i.e. semantic information at the word level) and derive - sentence and discourse interpretation". Reading comprehension then involves the same ability, $\stackrel{\infty}{\sim}$ but "relies on graphic-based information arriving through the eye" (Hoover \& Gough के 1990:131)

क्षे

Hoover and Gough (1990:127) contrast this simple view of reading with the view that reading .$\subseteq$ is a complex process involving higher mental processes not directly linked with language $\subseteq$ comprehension in general. The latter view Hoover \& Gough (1990:127) trace back to Huey. In comparing their simple view of reading with the view that emphasizes the complexity of the $\approx$ mental processes involved in reading comprehension, Hoover and Gough emphasize that the O simple view does not hold that reading is a simple matter. They $(1990: 128)$ point out that 它 graphic decoding is clearly no simple matter, as is evidenced by the difficulty some experience के in acquiring this skill. Also, linguistic comprehension itself is a complex process (Hoover \& Gough, 1990:128, 150, 151). For instance, they do not deny that the various subcomponents distinguished by Calfee \& Drum (1986) in their complex model form part of reading. Hoover and Gough's view is rather that all these "extra" skills are not specific to reading. Or, as put by Fries (1963:118), the higher level mental processes cited to form part of reading "may be developed and has been achieved by persons who could not read... [as] they are all matters of the uses of language and are not limited to the uses of reading". 
There is a considerable amount of empirical evidence to support the single comprehension process hypothesis. This empirical evidence takes the form of data which indicate that there is a strong direct correlation between listening and reading comprehension. Horowitz \& Samuels (1987:32) refer to a 1985 report which notes that listening comprehension can be a significant predictor of reading comprehension at later grades at school. They also refer to a study by Townsend, Carrithers, \& Bever (1987) which provides evidence that once a certain level of reading ability has been reached, reading comprehension and listening comprehension correlate. See also Perfetti (1987), and the references cited by him (1987:365). Three recent studies which provide similar evidence are (Hoover \& Gough 1990), (Vellutino et al. 1991), and (Stothard \& Hulme 1992). Each of these studies also contains several references to earlier works which presented empirical evidence to support the claim that reading and listening comprehension correlate.

Vellutino et al.'s (1991) study in particular provides extensive evidence of a correlation between reading and listening comprehension. Specifically, they (1991:107) found that for children who are approaching mastery level facility in word recognition (that is, who are mastering graphic decoding) listening comprehension was the primary predictor of reading comprehension. And vice versa: Performance on the reading comprehension task was the best predictor of performance on the listening comprehension task (Vellutino et al., 1991:110-111). They (1991:124) summarize and interpret their findings on the correlation between reading and listening comprehension in advanced readers as follows:

"As regards comprehension processes, the data indicate that the skills and abilities that underlie reading comprehension are essentially the same as the skills and abilities that underlie listening comprehension. Just as listening comprehension was the best predictor of performance on the reading comprehension test in advanced readers, so also was reading comprehension the best predictor of performance on the listening comprehension test, in all groups."

In their study of children with reading comprehension difficulties, Stothard \& Hulme (1992) found that the comprehension problems experienced by their group of poor comprehenders were not restricted to reading. This group also performed worse on the listening comprehension test than did the control group. Stothard \& Hulme (1992:254) summarize and interpret their findings as follows:

"We first wished to ascertain whether the children's comprehension problems were in anyway specific to reading. We have found unequivocally that they are not; our 
children showed marked deficits on spoken language comprehension tasks. This has important practical and theoretical implications. Theoretically, the origin of their comprehension. problems clearly lies in general purpose language processing mechanisms, and not in mechanisms specialised for reading."

In sum, then: The single comprehension process hypothesis has considerable empirical support, in the form of evidence that there is a direct correlation between reading comprehension and $£$ listening comprehension for readers who have mastered graphic decoding.

\subsection{Linguistic pragmatics: The general-purpose cognition hypothesis}

It has become virtually a truism that there is neither a unified field of pragmatics, nor a unified 官 view of what pragmatics is or ought to be (Nuyts, 1987:716; Verschueren, 1987:3-4; Levinson 1983:1-47). For the purpose of the present argument, however, our focus is on a fairly well$\infty_{\infty}$ defined set of pragmatic theories, namely those which aim to explain how utterances are finterpreted in context, and which assume that the interpretation process is to a large extent an Onferential one. Grice's $(1975 ; 1978)$ proposals on how one can mean more than what is said $\stackrel{\infty}{\sim}$ undoubtedly represent the best-known, and most influential, member of this set of pragmatic $\overline{\bar{D}}$ theories. Over the years many interpretations and variants of Grice's proposals have been put if forward, as well as some alternatives which, while they still adhere to the spirit of his original . $i d e a s$, nevertheless differ in crucial respects from his proposals. The former class includes, . Inter alia, Kasher's $(1982 ; 1991)$ and Green's $(1990)$ interpretation of Grice's proposals. The $\subseteq$ best-known member of the latter class is probably Sperber \& Wilson's (1986) relevance theory, 迹 theory which is currently attracting a great deal of attention within linguistic pragmatics.

There is clearly no space here to give a detailed exposition of either Grice's original proposals or of any of the later theories developed in response to these proposals. Similarly, no account $\frac{\Phi}{\bar{\Phi}}$ can be given here of the - undoubtedly important - differences among the various linguistic pragmatic theories belonging to the class of theories delimited here. Instead, I will present what is essentially a composite picture of the view of utterance interpretation developed within the "Gricean tradition" in linguistic pragmatics. I use the term "Gricean" here in a wide sense, to include also a theory such as Sperber and Wilson's relevance theory, which has been called "post-Gricean" (Barton 1990:155). Not all the points made below are made in exactly the same form in each of the theories developed within this tradition, and not all theories would put the same emphasis on each point. Nevertheless, the composite picture captures the essence of the most important pragmatic theories of utterance interpretation. Where appropriate, I will refer to the views of specific pragmaticists. 
The intended meaning of an utterance is determined in part by the grammar of the language in question. The meaning, or information, which a hearer can recover solely on the basis of his grammatical competence knowledge is contained in a so-called semantic representation. Recovery of this information is conceptualized as a decoding process, with the grammar of the language as the code.

Different pragmatic theories make different assumptions about precisely how much information can be recovered solely on the basis of linguistic knowledge - or to put it differently, how much information is linguistically encoded. Within the framework of Sperber and Wilson's relevance theory, for instance, the amount of information assumed to be recoverable solely on the basis of grammatical knowledge is less than that assumed to be recoverable within pragmatic theories that are more closely related to Grice's original proposals - see (Smith \& Wilson, 1992; Wilson \& Sperber, 1993) for some discussion.

There is, however, general agreement that the information contained in a semantic representation - that is, the information that is linguistically encoded - usually falls far short of the information which the speaker/writer intends to convey with this utterance. The most detailed account of the various respects in which the information contained in a semantic representation falls short of the full intended interpretation of an utterance, can be found in (Sperber \& Wilson, 1986: chapter 4). Aspects of the intended interpretation of an utterance not fully determined by a semantic representation include: (i) the intended meaning of any ambiguous expressions which occur in the utterance; (ii) the actual referents of any referring expressions in the utterance; (iii) the full interpretation of semantically vague expressions; (iv) the implicatures of the utterance; (v) the illocutionary force of the utterance; (vi) a possible metaphorical or ironical interpretation; (vii) the meaning of any stylistic effects.

The basic problem for any pragmatic theory is then to explain how, given the limited amount of information contained in the semantic representation of the sentence underlying an utterance, a hearer can determine what information a speaker intends to convey to him with the use of a specific utterance. This problem can be characterized in terms of the notion of 'bridging a gap': How does the hearer manage to bridge the gap between the limited information which can be obtained through linguistic decoding of an utterance and the information which the speaker intends to convey with the utterance?

The answer which Gricean pragmatic theories provide to this question goes more or less as follows: The semantic representation acts as a kind of blue-print, which the hearer must fill in 
in order to determine the full speaker intended meaning. This process of "filling in the blueprint" is not an algorithmic process, but is subject to risk. It is conceptualized as an inferential process, in which all kinds of assumptions can come into play. The class of assumptions which can play a role in the inferential interpretation process is in principle unlimited: Any assumption that forms part of the set of assumptions about the world which an individual holds at a particular moment can in principle be brought to bear on the interpretation of an utterance.

oThe interpretation of an utterance at which a hearer eventually anives will depend on which additional assumptions he used, as well as on the specific inferences made. Now, given the vast Frange of additional assumptions from which a hearer can choose and the vast number of Npotential inferences that can be made, the problem for a pragmatic theory of utterance Ginterpretation becomes that of specifying the principles which guide the inferential process, gincluding the selection of additional assumptions.

$\stackrel{\infty}{\circ}$

$\infty_{\infty} W$ ithin linguistic pragmatics, there is currently wide-spread agreement that the principles which fregulate the inferential component of utterance interpretation are not special-purpose principles. -These principles are not based on the properties of certain special forms of language use, for iexample conversational exchanges versus non-conversational exchanges, interactive versus nonGinteractive discourse, cooperative versus non-cooperative exchanges - see Green (1990:411git13) for some discussion. Rather, the principles which govern utterance interpretation are widely assumed to be general-purpose cognitive principles, with a much wider domain of .5application than any specific form of language use, and indeed much wider than language use Gitself (Chametzky 1992:67). There are different conceptualizations of the nature of these

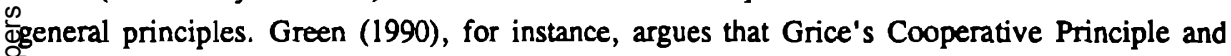
QThe maxims are principles defining rational behaviour, and that they apply to utterance प्रnterpretation simply as a special case. Kasher $(1982 ; 1991)$ argues that there is no need for of Grice's Cooperative Principle, since all the maxims derive from a general principle governing 产 $\omega_{\text {a general-purpose cognitive principle. Sperber \& Wilson (1986) argue that the principles which }}$ guide utterance interpretation are general cognitive principles which guide all information processing in the human mind. Indeed, their theory is first and foremost a theory of cognitive information processing. Utterance interpretation represents just a special case of the operation of these principles.

In sum: In terms of current linguistic pragmatic theories, utterance interpretation involves two distinct processes. In the first place, there is a process of linguistic decoding, which in some way or another relies on the grammatical knowledge of the user. In the second place, there is 
an inferential process in terms of which the information obtained via the linguistic decoding process is enriched and expanded in various ways. This inferential process can draw on any assumption contained in the vast store of assumptions about the world which an individual holds at that moment. The process in terms of which the information recovered through linguistic decoding is expanded and enriched via the use of additional assumptions is assumed to be governed by general-purpose cognitive principles, rather than special-purpose linguistic principles. It is the latter assumption which is of prime interest here. In what follows I will refer to this assumption in brief as the "general-purpose cognition hypothesis".

\section{The relation between the target hypotheses}

In referring to the relationship between (graphic) decoding and linguistic comprehension Hoover \& Gough (1990:130) highlight an important distinction, namely that between the components of a process and the relationships among these components.

"...the fact that decoding does not necessarily precede linguistic comprehension in terms of a description of reading process does not imply that decoding is not separate from linguistic comprehension in terms of a description of reading ability. Questions concerning the components of a given process are distinct from questions concerning the relationships of these components."

Both the single comprehension process hypothesis and the general-purpose cognition hypothesis make claims about the components of a specific process. To ask about the relation between these two hypotheses, is then in effect to ask whether their respective claims about the components of the processes in question are mutually compatible.

The general-purpose cognition hypothesis developed within linguistic pragmatics entails that the interpretation of all utterances is governed by the same general principles. The hypothesis states, after all, that the principles in question apply much more generally than language; indeed, their application in the case of utterance interpretation is merely a special case of their application. In effect, then, the general-purpose cognition hypothesis is incompatible with a claim that utterance interpretation in any specific form of language use is governed by principles specific to that form of language use. Of crucial importance for the present argument, is that this hypothesis is incompatible with any claim to the effect that the interpretation of spoken language is governed by principles which differ from those that govern written language. Any evidence that the interpretation of written and the interpretation of spoken language are governed by different principles would refute the general-purpose 
cognition hypothesis. Conversely, any evidence that the interpretation of written and the interpretation of spoken language are governed by the same set of principles would support this hypothesis. (Such evidence would, of course, also support a weaker hypothesis, namely that all utterance interpretation is governed by principles which are special to language, but general in the sense that they apply to all forms of language use. Within mentalist pragmatics, however, no detailed proposal based on this hypothesis is currently being put forward.)

In a sense, then, the general-purpose cognition hypothesis of linguistic pragmatics entails the single comprehension process hypothesis developed within reading comprehension research. N Consequently, all the empirical support for the single comprehension process hypothesis in gathered by reading comprehension researchers also provides indirect support for the generalpurpose cognition hypothesis of linguistic pragmatics.

$\ddot{\bar{\theta}}$

O One can also consider the relation between the single comprehension process hypothesis of $\mathrm{\infty}_{\infty}$ reading comprehension research and the general-purpose cognition hypothesis from another fiperspective. The single comprehension process hypothesis stipulates that the same skills and Tabilities underlie reading and listening comprehension. It does not, however, provide a N principled answer to the question of why the same skills and abilities should underlie both $\overline{0}$ reading and listening comprehension. This is so, because the single comprehension process . $h y$ hypothesis does not specify what the skills and abilities are that underlie linguistic comprehension. The general-purpose cognition hypothesis of linguistic pragmatics, however, does in part specify the nature of these skills and abilities. And its answer to the question of $\subseteq$ what the common skills and abilities are is of such a nature that it provides a principled answer $\frac{\mathscr{N}}{\mathbb{Q}}$ to the "why" question left unanswered by the single comprehension process hypothesis: The s skills and abilities which underlie reading and listening comprehension are the same because ज. these skills and abilities are not specific to any form of language use, and indeed not specific to language use at all. Rather they are general-purpose cognitive principles which apply to $\frac{\Phi}{\bar{\Phi}}$ language use as a special case.

In sum, then: The single comprehension process hypothesis and the general-purpose cognition hypothesis represent a significant convergence between recent work in reading comprehension and linguistic pragmatics. From the perspective of linguistic pragmatics: The general-purpose cognition hypothesis entails the single comprehension process hypothesis. Consequently, the empirical support for the latter hypothesis also provides support for the general-purpose cognition hypothesis. From the perspective of reading comprehension research: The generalpurpose cognition hypothesis provides part of the answer to the question of exactly what the skills and abilities underlying reading and listening comprehension are. It does so, moreover, 
in a way which provides a principled answer to the question of why the same skills and abilities should underlie both reading and listening comprehension. Before I turn to the significance of these points, I briefly outline two further respects in which there is a convergence between reading comprehension research and linguistic pragmatics. Both cases are closely linked to the two hypotheses discussed above.

\section{Two further Instances of convergence between reading comprehension research and linguistic pragmatics}

\subsection{The role of world knowledge in linguistic comprehension}

There is an extensive literature which documents the effect of non-linguistic knowledge - also called "background knowledge" or "world knowledge" - on reading comprehension. Vellutino et al.'s (1991) recent study of the various components of reading ability similarly provides such evidence. Thus, they (1991:107) report that measures of world knowledge contribute a substantial portion of the variance in their group of poor and normal readers. Similar findings were reported for listening comprehension (Vellutino et al., 1991:110). They (1991:127-8) conclude that "... semantically based skills such as vocabulary and world knowledge were... found to be the most powerful predictors of performance on both the reading and listening comprehension measures."

The fact that world knowledge is a reliable predictor for both reading and listening comprehension of course provides further support for the claim that the same skills and abilities underlie these two forms of linguistic comprehension. Our interest here, however, is in the fact that there is a correlation between world knowledge and comprehension, whether reading or listening. This finding fits in with the claims about linguistic comprehension made by the pragmatic theories discussed above. One of the central claims of these theories is that the information linguistically encoded in an utterances falls short of the full intended meaning of the utterance. In order to bridge the gap between the linguistically encoded meaning and the full intended meaning the interpreter - whether hearer or reader - has to engage in an inferential process in which non-linguistic assumptions of various kinds can play a role. The evidence of a correlation between world knowledge and both reading and listening comprehension provided by studies such as that of Vellutino et al.' (1991) supports the basic claim of pragmatic theories that non-linguistic knowledge plays a crucial role in utterance interpretation. 
Viewed from a different perspective, one could say that the linguistic pragmatic theories in question provide an answer to the question of why there should be a correlation between world knowledge and both. reading and listening comprehension. These theories make specific assumptions about what the linguistic form itself can contribute towards the overall interpretation, and provide an account of how non-linguistic knowledge is used in an inferential process which is to expand the "blue-print" provided by the linguistic form to the full intended meaning.

\subsection{The importance of linguistic identification processes in reading comprehension}

Since the 1970s the major focus in reading comprehension research was on the role which world knowledge (=background knowledge) and reader inferences play in text interpretation. In this connection, see for example the extensive literature on the role of scripts, frames, and schemas in discourse interpretation (Anderson \& Pearson, 1984; Oakhill \& Garnham, 1988:235). This work typically pays little or no attention to the linguistic aspects of the text. Caron's (1992:160-161) comments on a specific model of discourse processing is relevant here:

"...there is one criticism which can be levelled at this model - as, indeed, at all studies of text processing. This concems the purely conceptual level at which processing takes place. The specifically linguistic aspects of the text are ignored. Can the linguistic formulation of a discourse really be considered to have no role in its comprehension and memorization?".

Recent empirical work on reading comprehension provides evidence that "bottom-up" processing - that is, processing of the various elements in the text - is in fact a crucial component of reading comprehension. Grabe (1989:151-2), in a review of reading research in cognitive psychology, mentions several studies which argue for bottom-up processing in reading "as important components of the linguistic processing which defines reading." Grabe (1989:151-152) reviews a number of studies which specifically provide evidence that the identification of various elements in the text forms an important aspect of fluent reading comprehension abilities. He (1989:152) concludes his review of these studies as follows:

"In general, the above observations support the notion that reading is, fundamentally, a linguistic process. That is, if readers do not control the identification of linguistic forms and cannot recognize the linguistic structures, there is little that world knowledge can do to overcome these deficiencies. Thus, identification processes are a necessary, if not sufficient, component of reading abilities. Automatic, bottom-up processing is often 
overlooked in discussions of reading theory, particularly in second language contexts, but it is an essential aspect of fluent reading ability."

Vellutino et al.'s (1991:107) finding that grammatical ability, amongst other things, is a reliable predictor of text comprehension fits in with Grabe's conclusions. They (1991:128) report that the poor readers performance on the language and language dependent tests was lower than that of normal readers. They (1991:128) conclude that "..reading difficulties in otherwise normal children will, in most cases, be caused by deficiencies in one or more of the domains of language".

The finding that bottom-up processes, and specifically the identification of linguistic forms and linguistic structures, form an essential part of reading comprehension is quite in line with the claims which the inferential pragmatic theories outlined above make about utterance interpretation. It is true that all these theories assign an important role to inferencing in utterance interpretation, and that all claim that background knowledge, or world knowledge, contributes significantly to utterance interpretation. For all these theories, however, the inferential part of utterance interpretation - which is where non-linguistic knowledge comes into play - has as its starting point the information linguistically encoded in the utterance. Recovering the linguistically encoded information is therefore an essential part of utterance interpretation. And to recover the linguistically encoded information, the interpreter must correctly identify the linguistic form.

The finding that correct identification of the linguistic forms and structures in a text is a crucial component of reading comprehension can be said to provide some indirect support for the assumption of linguistic pragmatic theories that recovery of the linguistically encoded information associated with an utterance is an essential part of the interpretation process. Viewed from the perspective of reading comprehension research, the pragmatic theories reviewed in section 2.2 above provide an explanation for the finding that linguistic identification processes are an essential part of reading comprehension. These theories provide general accounts of utterance interpretation, irrespective of medium. And in terms of these theories identification of the linguistic structures and forms is an essential component of the interpretation process. The importance of bottom-up identification processes in reading comprehension is thus exactly what one would expect, given the basic assumptions of the inferential pragmatic theories under discussion here. 


\section{Conclusions and implications}

\subsection{Convergence and the criterion of inter-theory support}

The comparison presented in sections 3 and 4 above of recent work in reading comprehension research and in linguistic pragmatics reveals that there is a significant convergence between this work. Hypotheses about the mental skills and abilities underlying utterance interpretation odeveloped within linguistic pragmatics fit in with, and are indeed supported by, theoretical assumptions and empirical findings on the mental skills and abilities underlying reading Ncomprehension. Viewed from a different perspective, the claims made by linguistic pragmatic

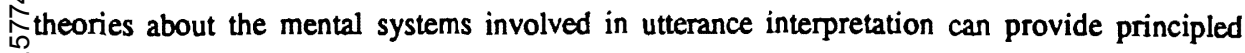
explanations for some of the findings of reading comprehension research.

$\ddot{\overline{0}}$

DTe significance of the convergence between reading comprehension research and linguistic $\infty_{\infty}$ pragmatics with respect to the mental systems and processes underlying linguistic fcomprehension is enhanced by two factors. In the first place, as noted in section 1 above, there $\stackrel{\text { O }}{-}$ has been very little contact between reading comprehension research and linguistic pragmatics. Ninsofar as they have arrived at similar conclusions about the skills and abilities underlying Ōlinguistic comprehension, they have done so independently from each other. In the second if place, reading comprehension research and linguistic pragmatics have arrived at similar conclusions by means of rather different research methods. Reading comprehension research Darrived at the relevant findings by employing the methods of experimental psychology, namely $\subseteq$ experimental studies with the accompanying statistical treatment of results. Linguistic कू pragmatics arrived at its conclusions by using the traditional method of linguistics, namely by $\therefore$ testing the predictions of theoretical claims against the linguistic intuitions of language users 品 see e.g. (Bechtel, 1987:295) for a brief characterization of the research methods typical of the 늘 two fields of inquiry.

के

One effect of the current interdisciplinary isolation within language research is that an important criterion of theory appraisal - that of inter-theory support - plays at best a very limited role in the appraisal of theories about some aspect of language and language use. It is one of the desiderata of a scientific theory that it can be "fitted into the body of theory already established" (Kaplan 1964:314). Or as Newton-Smith (1981:228) puts it, "[i]t counts in favour of a theory that it supports a successful extant theory". By the same token, "[i]t counts against a pair of theories if no matter how successful they are in their own domains they clash in the sense that they cannot be consistently worked together in domains of common application" (Newton-Smith 1981:228). 
The convergence between reading comprehension research and linguistic pragmatics outlined above suggests that the criterion of inter-theory support could in fact play a more important role in the appraisal of reading comprehension theories and linguistic pragmatic theories than has been the case up to now While the criterion of inter-theory support, on the basis of the common ground outlined above, does not make it possible to identify a specific reading comprehension theory and a specific pragmatic theory as more highly valued than the available alternatives, it does make it possible to identify certain classes of theories in the respective subfields as more highly valued than the alternatives. More specifically, it counts in favour of any theory of reading comprehension which incorporates the single comprehension process hypothesis and any pragmatic theory which incorporates the general-purpose cognition hypothesis that they "fit together". More generally, the fact that recent assumptions about the components of reading comprehension "fit in with" recent assumptions about the components of utterance interpretation in general counts in favour of both sets of assumptions.

The common ground between reading comprehension research and linguistic pragmatics, as well as the important metatheoretical implications which follow from it, is as yet unrecognized. The question arises now what benefits either or both of reading comprehension research and linguistic pragmatics could derive from a conscious attempt to explore and develop the connections between them. In section 5.2 this question is considered with the aid of a concrete illustration. In section 5.3 the question is discussed in more general, metatheoretical terms.

\subsection{Linking-up reading comprehension research and linguistic pragmatics: An illustration}

There is an important issue facing both the single comprehension process hypothesis and any pragmatic theory which claims that the same mental systems and processes are involved in utterance interpretation, irrespective of modality. This issue is the effect which certain differences between spoken and written language have on the interpretation of these two types of language.

There are numerous discussions of the differences between spoken and written language. For some recent discussions, see e.g. (Horowitz and Samuels, 1987:6 ff.; Townsend at al., 1987:218; Danks \& End, 1987:272; Samuels 1987; Oakhill \& Gamham, 1988:4; Hoover \& Gough, 1990:153). The differences between reading and writing mentioned by these authors include: (i) the impoverished systems of suprasegmentals in written language in comparison with the rich system in speech; (ii) the transitoriness of the signal in speech versus the 
permanent nature of the written signal, which makes review of earlier input easier in the case of written language; (iii) differences in the interpretation of deictic terms; (iv) the greater opportunity for interaction between speaker and hearer than between writer and reader. Those who propose the single comprehension process hypothesis are not unaware of these differences and of the need to account for them. So. for instance, Hoover and Gough (1990:153) take great pains to explain that the simple view does not claim that exactly the same procedures used in linguistic comprehension are used in reading comprehension. They do, however, claim that $\infty$ the differences that exist are "relatively minor in comparison to the great similarities between o

ine of the differences between spoken and written language which has attracted a great deal of attention relates to the role of context in determining the meaning of utterances - see (Horowitz $\because$ \& Samuels, 1987) for an overview. There are several scholars who put forward the view that,

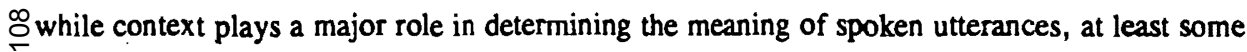
ळं forms of written language - specifically the school-literate text - have no context. Such forms J्of written language are claimed to be decontextualized. Consequently, it is claimed, the -meaning of such written language is determined a in radically different way from that of

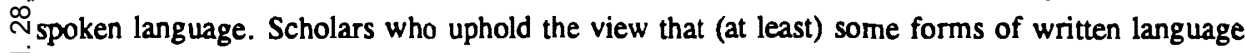
$\bar{S}$ are decontextualized, with the implication that the interpretation of such forms of written Ijlanguage is fundamentally different from that of spoken language, include Olson (1977), Watson \& Olson (1987), Scinto (1986:chapter 3), Michaels (1981), Chafe (1982; 1985), Stubbs (1980:109), and Cummins and Swain (1986:152-153).

The question of the role of context in the comprehension of written language is of both $\therefore$ theoretical and practical importance. As regards its theoretical importance: If it were to be true S. C. written language, then the single comprehension process hypothesis of reading comprehension के would face a serious challenge. Also, assumptions about the alleged decontextualized nature of written language have important implications for conceptions of literacy - see e.g. (Olson, 1977; 1991; Halverson, 1991; Street, 1984; Säljö, 1988), for some views on this matter. As regards the practical importance of the view that some forms of written language are decontextualized: Clearly, the implications for learning to read of this view are quite different from that of the single comprehension process hypothesis - see (Horowitz \& Samuels, 1987:38) for some general comments on this issue. The view that language is decontextualized implies that learning to read in part involves leaming to deal with a new form of language, namely decontextualized language, for which special comprehension skills are required. Instruction should therefore be aimed at the acquisition of new comprehension skills, specific to reading 
comprehension - see e.g. (Michaels 1981:424). The single comprehension process hypothesis, in contrast, implies that instruction which facilitates listening comprehension should facilitate reading comprehension - see e.g. (Hoover \& Gough, 1990:153; Vellutino et al., 1991:129).

Clearly, then, a proper understanding of the role of context in the comprehension of written and spoken language is of great theoretical and practical importance for reading comprehension research. Recent developments in linguistic pragmatics do, in fact, provide us with greater clarity on this issue. In essence: Recent work within linguistic pragmatics has made it possible to identify two major flaws in the argument that written language is fundamentally different from spoken language with respect to context. First: The argument is based on an inadequate notion of 'context'. By focusing on the physical situation in which an utterance is produced the context of production - the argument obscures the fact that what affects the interpretation of a spoken utterance is what is "in the mind" of the hearer. Moreover, by focusing on the external environment the argument for the decontextualized nature of written language underestimates the contribution of various kinds of background knowledge not derived from the situation of utterance in the interpretation of spoken utterances. Second: The claim that certain forms of written language can be fully explicit, with no reliance on context for their meaning, overestimates how much of the meaning of an utterance can be linguistically encoded and simultaneously underestimates the extent of the contribution of contextual assumptions to utterance interpretation. Extensive argumentation in support of all these points is presented in (Sinclair, 1993).

Instead of equating 'context' with the physical situation of utterance, recent work in pragmatics defines the context for the interpretation of an utterance as a subset of the assumptions about the world which an individual has in his mind at any particular moment - see (Sinclair (1993:533-535) for references and discussion. This "superset" of assumptions includes assumptions obtained through perceptual processing of the context of production and through processing of earlier parts of the discourse, plus all the assumptions stored in long-term memory. Assumptions supplied from an individual's memory, in Blakemore's (1992:18) words, "range from strongly evidenced assumptions derived through perception to guesses and hypotheses. They include memories of particular occasions and about particular individuals, general cultural assumptions, religious beliefs, knowledge of scientific laws, assumptions about the speaker's emotional state and assumptions about other speakers' perception of your emotional state." Once one looks at context in this light, the only difference between spoken and written language with respect to context is that the physical context of production is a source of potential contextual assumptions for the interpretation of spoken utterances, but not (normally) for written utterances. The crucial point, though, is that for both spoken and written 
language the context for the interpretation of an utterance is a subset of the assumptions about the world which an individual has in his mind at the moment of interpreting the utterance.

The arguments presented in (Sinclair, 1993) against the view that certain forms of written language are decontextualized and hence fully explicit illustrate how a link-up between linguistic pragmatics and reading comprehension research can benefit the latter: By making use of linguistic pragmatic work on the notion of 'context' and its effect on utterance interpretation, insight can be gained into the question of the role of context in written language. As a result, a potential problem for the single comprehension process hypothesis can be defused.

The development of a psychological notion of 'context' by recent pragmatic theories has an important consequence also for such theories, and for their relation to reading comprehension research. This psychological notion of 'context' immediately ties in linguistic pragmatic work on the role of context in utterance interpretation with research on the role of background knowledge in reading comprehension. As a result, the evidential base of linguistic pragmatic theories is, in principle at least, considerably expanded. Given that linguistic pragmaticists rely primarily on linguistic intuitions in justifying their theories, such an expansion of the data base of their theories to include data of quite a different sort would clearly be of benefit to linguistic pragmatics.

\subsection{Linking-up reading comprehension research and linguistic pragmatics: A metatheoretical perspective}

When trying to answer the question of what benefits either or both of reading comprehension research and linguistic pragmatics could gain from closer interdisciplinary contact, it is instructive to consider the relation between reading comprehension research and linguistic pragmatics against the background of the relation between linguistics and psychology. Reading comprehension research falls within the domain of psychology, while linguistic pragmatics in many respects - and particularly as regards its use of linguistic intuitions as its primary source of evidence - falls within the domain of linguistics. The relation between psychology and linguistics is, of course, quite complex and the subject of much controversy - see e.g. (Bechtel, 1987; Reber, 1987; McCauley, 1987; Abrahamsen, 1987; Tanenhaus, 1988), to mention but a few examples of works which address this relation. For the purpose of the present discussion, however, Abrahamsen's (1987) account of the relation between psychology and linguistics provides a useful frame of reference. 
Abrahamsen identifies a number of "boundary-bridging" relations between psychology and linguistics. Boundary-bridging contact, according to Abrahamsen (1987:370-371), always occurs "to satisfy the goals of one discipline by using results from the other discipline". Work that involves boundary-bridging between psychology and linguistics, constitutes psycholinguistics (Abrahamsen, 1987:370).

One type of "boundary-bridging" between psychology and linguistics identified by Abrahamsen (1987:374) occurs when linguists use psychological evidence to provide additional support for their hypotheses. Recall that linguistic pragmatic accounts of utterance interpretation are justified mainly on the basis of the linguistic intuitions of competent language users. As was argued above, evidence collected within reading comprehension research can be used to provide additional support for linguistic pragmatic theories. To put it differently: Evidence from reading comprehension research can serve as an important additional source of evidence for the appraisal of linguistic pragmatic accounts of utterance interpretation. In this connection one could consider, for example, the use of evidence derived from reading comprehension research on the role of background/world knowledge in the appraisal of claims made by linguistic pragmatic theories about the role of context in utterance interpretation - see the discussion in section 5.2 .

Another type of boundary-bridging contact between psychology and linguistics identified by Abrahamsen (1987:373-4) occurs when psychologists make use of linguistic descriptions. In the case under discussion, such boundary-bridging would occur when reading comprehension researchers make use of pragmatic analyses of certain phenomena when investigating reading comprehension. The use of linguistic pragmatic insights into the nature and role of context by reading comprehension researchers trying to come to terms with an alleged difference between the interpretation of written and spoken language, as outlined in section 5.2 above, provides an illustration of this type of boundary-bridging contact between reading comprehension research and linguistic pragmatics.

Boundary-bridging contact between reading comprehension research and linguistic pragmatics which involves the use of pragmatic analyses by reading comprehension researchers appears to have great potential. Linguistic pragmatic theories provide detailed accounts of exactly what contribution the elements in an utterance can make toward the overall interpretation of that utterance, and what non-linguistic assumptions are required to bridge the gap between the linguistic meaning of the utterance and its intended interpretation. Reading comprehension research on the role of, for example, world knowledge or inferencing in text comprehension could potentially benefit from using the "tools" provided by such pragmatic theories for more 
fine-grained analyses of the stimulus - that is, the text to be interpreted. There is, for instance, a considerable body of work on the role of inferencing in reading comprehension; which includes attempts to characterize the nature of the various inferences made during the reading process - see e.g. (Noordman and Vonk, 1992). Linking up such work with linguistic pragmatic work on inferencing in utterance interpretation might not only provide reading comprehension researchers with useful tools for investigating questions about inferencing in reading comprehension, but might even suggest new questions to be investigated.

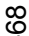

The two types of boundary-bridging contacts between reading comprehension research and

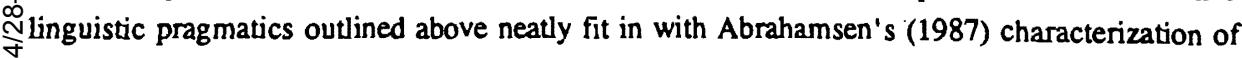
the relation between psychology and linguistics. The analysis presented in sections 3 and 4 above indicates that there is the potential for another type of boundary-bridging contact ᄒbetween reading comprehension research and linguistic pragmatics. It was suggested above that olinguistic pragmatic theories can explain some of the findings of reading comprehension $\underset{\infty}{\infty}$ research. It does so mainly by placing the findings of reading comprehension research, and the "components postulated as part of reading comprehension, within a wider context - namely, that of the skills and abilities which underlie utterance interpretation in general. In this respect the i relation between reading comprehension research and linguistic pragmatics differs from that of jंpsychology and linguistics, as sketched by Abrahamsen (1987). She (1987:374) claims that it is ij psychology which can provide explanations for linguistic facts, while in the case under .

裿

$\subseteq$ Abrahamsen's views on the use of psychology as a source of explanation by linguistics are $\frac{\omega}{\omega}$ based on a particular conceptualization of the relation between the disciplines of psychology $\frac{\circ}{\sigma}$ and linguistics. In terms of her (1987:361) specialization hierarchy for disciplines, linguistics is 든 the more specialized discipline, and psychology the less specialized discipline. She (1987:371) ocharacterizes the relation between (adjacent) disciplines in her hierarchy as follows:

\footnotetext{
"In general, the less specialized discipline reaches upward to obtain a description and other domain-specific analysis from the more specialized discipline, and the more specialized discipline sometimes reaches downward to obtain sources of explanation and confirmation in the less-specialized discipline."
}

With regard to the use of pragmatic analyses by reading comprehension research and the use of evidence from reading comprehension research by linguistic pragmatics the relation between reading comprehension research and linguistic pragmatics neatly fits this general picture. With respect to the use of sources of explanation, the picture is more complex. The reason why the 
relation between reading comprehension research and linguistic pragmatics at this point fails to fit Abrahamsen's characterization of the relation between psychology and linguistics is not difficult to find. Linguistic pragmatic theories do not merely make claims about the structure of language, as Abrahamsen's (1987:357) claims to be the case for linguistics. Rather, pragmatic theories make claims about mental systems and processes, just like reading comprehension theories. And insofar as they make claims about mental systems and processes, pragmatic theories are in a sense the more general theories. They provide an overall account of utterance interpretation, while reading comprehension theories make claims about the interpretation of a subset of utterances, namely those that are written. Viewed from this perspective, it is then not surprising that linguistic pragmatic theories can provide explanations for some of the findings of reading comprehension research.

It must not be concluded that theories of reading comprehension cannot also provide explanations for the findings of linguistic pragmatics. Linguistic pragmatics does not provide an account of the on-line processes involved in utterance interpretation, while reading comprehension research is, amongst other things, concerned with such on-line processes. For some pragmatic theories - notably Sperber \& Wilson's (1986) relevance theory - psychological factors such as memory and processing costs play a central role in its accounts of utterance interpretation. With regard to these factors, psychological theories, including theories about the on-line processes of reading comprehension, could also function as a source of explanation for lingu stic pragmatics.

When one considers the potential for closer cooperation between reading comprehension research and linguistic pragmatics, it is significant that some of the traditional barriers to closer cooperation between linguistics and psychology do not apply in the case of reading comprehension research and linguistic pragmatics. One of the most important of these barriers is what Reber. (1987:331) calls "isolationism". Referring specifically to attempts to link up Chomsky's work on grammatical competence with psychology, Reber (1987:331) characterizes isiolationism and its effects as follows:

"The Chomsky-inspired psycholinguistics views language as the ultimate unique behavior for it is conceptualized as doubly isolated from other psychological processes. Not only is language viewed as unique to man... but it is also viewed as unique within man. This position is actually a corollary of the content specific nativism in that the knowledge base hypothesized is encapsulated and only serves language; it is not seen as containing anything in the way of general processing systems. The resulting psycholinguistic science here becomes one in which nothing about language can be 
learned by the examination of any other cognitive or perceptual process $\ldots$ and vice versa."

The mental systems and processes postulated by linguistic pragmatic theories to account for utterance interpretation are not claimed to be unique and isolated within the mind. Language use, and utterance interpretation in particular, is assumed to reflect the operation of generalpurpose cognitive principles. From the perspective of pragmatic theories which incorporate this the assumption that there is a unique, special-purpose system in the mind in which knowledge of grammar, also called the "computational aspect of language", is stored. Mentalist pragmatic theories such as Kasher's and Sperber and Wilson's, while committed to the general-purpose cognition hypothesis, nevertheless assume that there is a special-purpose language system in the mind - see (Sinclair 1994) for some discussion of this point.

\subsection{Concluding remarks}

$\stackrel{\infty}{\sim}$

All in all, then, there is considerable potential for fruitful cooperation between reading comprehension research and linguistic pragmatics. While the two fields have - independently from each other .. converged on some significant common ground, explicit recognition and exploitation of potential links promises to benefit both reading comprehension research and linguistic pragmatics in various ways. Ultimately, a link-up between the two subfields of language research holds out the promise of advancing our insight into the mental skills and abilities which underlie the comprehension of natural language utterances.

\section{Acknowledgement}

I am grateful to Henriētte Murray for her useful comments on an earlier version of this text. 


\section{References}

Abrahamsen, Adele A. (1987). Bridging boundaries versus breaking boundaries: Psycholinguistics in perspective. Synthese, 72, 355-388.

Anderson, Richard C. \& Pearson, David P. (1984). A schema-theoretic view of basic processes in reading comprehension. In David P. Pearson (Ed), Handbook or Reading Comprehension, pp. 255-291. New York, London: Longman.

Barton, Ellen L. (1990). Nonsensential constituents. A theory of grammatical structure and pragmatic interpretation. Amsterdam/Philadelphia: John Benjamins.

Bechtel, William. (1987). Psycholinguistics as a case of cross-disciplinary research: Symposium introduction. Synthese, 72, 293-311.

Blakemore, Diane. (1992). Understanding utterances. Oxford: Basil Blackwell.

Calfee, R. \& Drum, P. (1986). Research on teaching reading. In M. Wittrock (Ed), Handbook of research on teaching, pp. 804-849. 3rd edition. New York: Macmillan.

Caron, Jean. (1992). An introduction to psycholinguistics. New York, etc.: Harvester Wheatsheaf.

Castelfranchi, Cristiano \& Poggi, Isabella. (1987). Communication: Beyond the cognitive approach and speech act theory. In Jeff Verschueren \& Marcella Bertucelli-Papi (Eds), The Pragmatic Perspective. Selected Papers from the 1985 International Pragmatics Conference, pp. 239-254. Amsterdam/Philadelphia: John Benjamins.

Chafe, Wallace L. (1982). Integration and involvement in speaking, writing and oral literature. In Deborah Tannen (Ed), Spoken and written language: Exploring orality and literacy, pp. 35-52. Norwood, NJ.: Ablex.

Chafe, Wallace L. (1985). Linguistic differences produced by differences between speaking and writing. In David R. Olson, Nancy Torrance \& Angela Hildyard (Eds), Literacy, language and learning: The nature and consequences of reading and writing, pp. 105123. Cambridge: Cambridge University Press. 
Chametzky, Robert. (1992). Pragmatics, prediction, and Relevance. Journal of Pragmatics, 17, 63-72.

Cummins, Jim \& Swain, Merrill. (1986). Bilingualism in education. London: Longman.

Danks, Joseph H. \& End, Laurel J. (1987). Processing strategies for reading and listening. In Rosalind Horowitz \& S. Jay Samuels (Eds), Comprehending oral and written language,

Davis, Steven. (1991). Introduction. In Steven Davis (Ed), Pragmatics. A reader, pp. 3-13. New York, Oxford: Oxford University Press.

Fries, C. (1963). Linguistics and Reading. New York: Holt, Rinehart \& Winston.

Grabe, William. (1989). Literacy in a second language. Annual Review of Applied Linguistics, $10,145-162$.

Green, Georgia. (1990). The universality of Gricean interpretation. Proceedings of the Sixteenth Annual Meeting of the Berkeley Linguistics Society, 411-428.

Grice, H.P. (1975). Logic and conversation. In P. Cole \& J.L. Morgan (Eds), Syntax and semantics, 3: Speech acts, pp. 41-58. New York: Academic Press

Grice, H.P. (1978). Further notes on logic and conversation. In P. Cole (Ed), Syntax and semantics 9: Pragmatics, pp. 113-127. New York: Academic Press.

Halverson, John. (1991). Olson on literacy. Language in Society, 20, 619-640.

Hoover, Wesley A. \& Gough, Philip B. (1990). The simple view of reading. Reading and Writing: An interdisciplinary Journal, 2, 127-160.

Horowitz, Rosalind \& Samuels, S. Jay. (1987). Comprehending oral and written language: Critical contrasts for literacy and schooling. In Rosalind Horowitz \& S. Jay Samuels (Eds), Comprehending oral and written language, pp. 1-52. San Diego: Academic Press. 
Kaplan, Abraham. (1964). The conduct of inquiry. Methodology for behavioral science. New York: Chandler.

Kasher, Asa. (1982). Gricean inference revisited. Philosophica, 29, 25-44.

Kasher, Asa. (1991). Pragmatics and the modularity of the mind. In Steven Davis (Ed), Pragmatics: A reader, pp. 567-582. New York, Oxford: Oxford University Press.

Levinson, Stephen C. (1983). Pragmatics. Cambridge: Cambridge University Press.

McCauley, Robert N. (1987). The not so happy story of the marriage of linguistics and psychology or Why linguistics has discouraged psychology's recent advances. Synthese, 72, 341-353.

Michaels, S. (1981) Sharing time: Children's narrative styles and differential access to literacy. Language \& Sociery, 10, 423-442.

Morgan, Jerry L. \& Green, Georgia M. (1989). Pragmatics and reading comprehension. In Rand J. Spiro, Bertram C. Bruce, \& Willaim F Brewer (Eds), Theoretical issues in reading comprehension. Perspectives from cognitive psychology, linguistics, artificial intelligence, and education, pp. 113-140. Hillsdale, N.J. Lawrence Erlbaum.

Newton-Smith, W.H. (1981). The rationality of science. London: Routledge \& Kegan Paul.

Noordman, Leo G.M. \& Vonk, Wietske. (1992). Reader's knowledge and the control of inferences in reading. Language and Cognitive Processes, 7, 373-391.

Nuyts, Jan. (1992). Aspects of a cognitive-pragmatic theory of language. On cognition, functionalism, and grammar. Amsterdam/Philadelphia: John Benjamins.

Nuyts, Jan. (1987). Pragmatics and cognition: On explaining language. In Jeff Verschueren \& Marcella Bertucelli-Papi (Eds), The Pragmatic Perspective. Selected Papers from the 1985 Intemational Pragmatics Conference, pp. 715-732. Amsterdam/Philadelphia: John Benjamins.

Oakhill, Jane \& Gamham, Alan. (1988). Becoming a skilled reader. Oxford: Basil Blackwell. 
Olson, David. (1977). From utterance to text: The bias of language is speech. and writing. Harvard Educational Review, 47, 257-281.

Olson, David. (1991). Children's understanding and the autonomy of written texts. Text, 11, 3-23.

Perfetti, Charles. (1987). Language, speech, and print: Some asymmetries in the acquisition of $\infty \quad$ literacy. In Rosalind Horowitz \& S. Jay Samuels (Eds), Comprehending oral and written language, pp. 355-369. San Diego, etc.: Academic Press.

Reber, Arthur S. (1987). The rise and (surprisingly) rapid fall of psycholinguistics. Synthese, 72, 313-339.

Säljö, Roger (Ed). (1988). The written world: Studies in literate thought and action. Orlando: Academic Press.

Samuels, S. Jay. (1987). Factors that influence listening and reading comprehension. In Rosalind Horowitz \& S. Jay Samuels (Eds), Comprehending oral and written language, pp. 295-325. San Diego etc.: Academic Press.

Scinto, Leonard F.M. (1986) Written language and psychological development. Orlando: Academic Press.

Sinclair, Melinda. (1993). Are academic texts really decontextualized and fully explicit? A pragmatic perspective on the role of context in written communication. Text, 13, 529 558.

Sinclair, Melinda. (1994). Fitting pragmatics into the mind. Some issues in mentalist pragmatics. [To appear in Joumal of Pragmatics.]

Smith, Neil \& Wilson, Deirdre. (1992). Introduction. Lingua, 87, 1-10.

Sperber, Dan \& Wilson, Deirdre. (1986). Relevance: Communication and cognition. Oxford: Basil Blackwell. 
Stothard, Susan \& Hulme, Charles. (1992). Reading comprehension difficulties in children. The role of language comprehension and working memory skills. Reading and Writing: An Interdisciplinary Journal, 4, 245-256.

Street, Brian V. (1984). Literacy in theory and practice. Cambridge: Cambridge University Press.

Stubbs, Michael. (1980). Language and literacy: The sociolinguistics of reading and writing. London: Routledge \& Kegan Paul.

Tanenhaus, Michael K. (1988). Psycholinguistics: An overview. In Frederick J. Newmeyer (Ed), Linguistics: The Cambridge Survey. Vol. III. Language: Psychological and biological aspects, pp. 1-37. Cambridge: Cambridge University Press.

Townsend, David J., Carithers, Caroline, \& Bever, Thomas G. (1987). Listening and reading processes in College- and Middle School-age readers. In Rosalind Horowitz \& S. Jay Samuels (Eds), Comprehending oral and written language, pp. 217-242. San Diego etc.: Academic Press.

Vellutino, Frank, Scanlon, Donna M., Small, Sheila, \& Tanzman, Melinda S. (1991). The linguistic bases of reading ability: Converting written to oral language. Text, 11, 99133.

Verschueren, Jeff. (1987). The pragmatic perspective. In Jeff Verschueren \& Marcella Bertucelli-Papi (Eds), The Pragmatic Perspective. Selected Papers from the 1985 International Pragmatics Conference, pp. 3-8. Amsterdam/Philadelphia: John Benjamins.

Watson, Rita \& Olson, David. (1987). From meaning to definition: A literate bias on the structure of word meaning. In Rosalind Horowitz \& S. Jay Samuels (Eds), Comprehending oral and written language, pp. 329-353. San Diego: Academic Press.

Wilson, Deirdre \& Sperber, Dan. (1993), Linguistic form and relevance. Lingua, 90, 1-25. 